\title{
EHMTI-0074. Excessive daytime sleepiness in migraineurs is associated with anxiety and depression: a population-based study
}

\author{
M Chu ${ }^{1 *}$, BK Kim², JW Park ${ }^{3}, \mathrm{JM} \mathrm{Kim}^{4}$ \\ From 4th European Headache and Migraine Trust International Congress: EHMTIC 2014 \\ Copenhagen, Denmark. 18-21 September 2014
}

\section{Introduction}

Excessive daytime sleepiness is a major clinical and health concern that can have harmful consequences and has shown an associated with anxiety and depression. A close relationship between EDS and migraine has been reported in case-control studies. Case-control study may be affected by confounding factors.

\section{Aims}

To examine whether excessive daytime sleepiness (EDS) in migraineurs is associated with anxiety and depression in a population-based sample.

\section{Methods}

We selected a stratified random population sample of Koreans aged 19-69 and evaluated them with a 60-item semi-structured interview designed to identify headache type, anxiety, depression and EDS. Subjects with EDS was identified if a subject's Epworth Sleepiness Scale (ESS) was 10 or more. Anxiety and depression symptoms were evaluated using Goldberg Anxiety Scale questions and Patient Health Questionnnaire-9, respectively.

\section{Results}

The 1-year prevalences of EDS and migraine were 16.8\% and $5.4 \%$, respectively. Migraineurs reported more commonly reported EDS compared to non-migraine subjects (25.2\% vs. $16.3 \%, p=0.005)$. Migraineurs with EDS reported higher attack frequency per month $(6.0 \pm 8.5 \mathrm{vs}$. $3.5 \pm 5.8, \mathrm{p}=0.010)$, higher HIT-6 score $(60.0 \pm 10.1$ vs. $52.6 \pm 8.3, \mathrm{p}<0.001)$ compared to migraineurs without EDS. Logistic regression analysis revealed that migraine showed an odds ratio (OR) for EDS compared to nonmigraineurs $(\mathrm{OR}[\mathrm{CI}])=1.7[1.2-2.6])$. After adjusting anxiety and depression, migraine was not associated with $\operatorname{EDS}(\mathrm{OR}[\mathrm{CI}])=1.3[0.8-1.9])$.

\section{Conclusions}

Approximately $1 / 4$ of migraineurs experienced EDS. Excessive daytime sleepiness in migraineurs was associated with anxiety and depression.

No conflict of interest.

\section{Authors' details}

${ }^{1}$ Neurology, Hallym University Sacred Heart Hospital, Anyang, Korea.

${ }^{2}$ Neurology, Eulji University School of Medicine, Seoul, Korea. ${ }^{3}$ Neurology, The Catholic University of Korea, Uijeongbu, Korea. ${ }^{4}$ Neurology, Chungnam National University, Daejeon, Korea.

Published: 18 September 2014

\section{doi:10.1186/1129-2377-15-S1-D9}

Cite this article as: Chu et al.: EHMTI-0074. Excessive daytime sleepiness in migraineurs is associated with anxiety and depression: a populationbased study. The Journal of Headache and Pain 2014 15(Suppl 1):D9. 